\title{
From "Forgotten and Ignored" to Standards and Certification: Gerontological Counseling Comes of Age
}

\author{
Jane E. Myers
}

\begin{abstract}
The specialty of gerontological counseling has a 20-year history that began with a dearth of information and has progressed to the development of preparation standards and a national certification, both based on a nationally endorsed statement of competencies for gerontological counselors. The question of whether generalization or a specialization will best serve the needs of older persons continues to be central to the development of this specialization.
\end{abstract}

B lake and Kaplan (1975, p. 156) issued a challenge to the counseling profession that began with the statement that "Older people are the forgotten and ignored of APGA" (the American Personnel Guidance Association; now the American Counseling Association, ACA). This article describes two decades of response to that challenge, including five national projects on aging, interest groups in each ACA division, a new division with the adult years as a focus, new graduate courses, a statement of competencies, professional preparation standards, specialty accreditation, and a national certification in gerontological counseling. These developments have led to the emergence of gerontological counseling as a recognized specialty within the counseling profession. This article provides an overview of the historical development of gerontological counseling and the current status of this specialty.

\section{THE NEED FOR A SPECIALTY}

The aging of the U.S. population is a frequent topic of conversation in both formal and informal gatherings. Whereas only $4 \%$ of the population in the United States were over age 65 in 1900, almost $13 \%$ are over 65 today (American Association of Retired Persons, 1995). It is estimated that $20 \%$ of the population will be in this age group by the year 2050 , and an estimated $50 \%$ of persons will be over the age of 50 by the year 2000 (Special Committee on Aging, 1983). There are few aspects of society untouched by these demographic shifts. As a result, most academic disciplines and professions have begun to study the older population and the aging process.

As the life span has increased, counselors have moved from a primary focus on school populations to an equally strong emphasis on community-based programs addressing the mental health concerns of persons across the life span (Palmo, Weikel, \& Brooks, 1995). Counselors have begun to work with older persons, and the question has emerged of whether and how such work is different from counseling with any other population. Burns and Taube (1990) noted that the extent of mental health needs does not seem to change with age, and Knight (1989) determined that psychotherapy is as effective with older persons as with people of any age group. If age is not a factor in therapy outcome, as Thompson (1987) suggested, then it could be argued that special training to work with older people may not be necessary.

On the other hand, Waters (1984) identified both similarities and differences in counseling with older and younger persons. Numerous authors have written concerning specialized techniques for use with older people (e.g., Brammer, 1985; Burnside, 1984; Herr \& Weakland, 1979), presumably based on different needs of this population. A major difference is the reluctance of older persons to seek counseling (Cohen, 1977). In addition, the reluctance of therapists to treat older people has been documented (Poggi \& Berland, 1985). As a group, older people are substantially underserved by mental health practitioners (Flemming, Rickards, Santos, \& West, 1986), in part because of negative attitudes (Piggrem \& Schmidt, 1982) and in part because of lack of specialized training (Myers \& Blake, 1986). Kunkel and Williams (1991) identified an additional barrier to services as the lack of research-informed theoretical perspectives on how to provide mental health services most effectively to older people and how to encourage older people to use such services. In short, the numbers of older persons have continued to increase, whereas mental health services for this population have remained uniformly inadequate.

\section{HISTORICAL DEVELOPMENT OF GERONTOLOGICAL COUNSELING}

In 1972, the ACA (then APGA) Senate passed a resolution mandating the association to develop guidelines for curriculum planning to train counselors to work with older people (Howard-Jasper, 1981). The following year, ACA established a special committee to serve for 1 year to develop a strategy for implementing this resolution. The Commission on Middle-Aged and Older Persons survived in some form as a special committee for the next 16 consecutive years, finally being called the "Committee on Adult Development and Aging."

In 1975 , only 18 , or $6 \%$, of all counselor preparation programs reported offering even an elective course in gerontological counseling (Salisbury, 1975). Prior to that time, there were few articles in the professional counseling literature addressing the counseling needs of older clients. Most of these articles dealt with "older workers," the group the federal government defines as persons aged 40 years and above. The lack of training programs, the growth of the older population, and the challenge issued by Blake and Kaplan (1975) merged to create a climate within which specialized counseling for older persons began to be explored.

ACA responded to the dearth of information related to counseling with older persons by seeking funding from the U.S. Administration on Aging (AoA) to develop curricula for training counselors to work with older persons. Between 1978 and 1990, the AoA funded five national projects on aging to ACA, for a total of more than $\$ 1$ mil- 
Reprinted from Myers, J. E. (1995). From 'Forgotten and Ignored' to standards and certification:

Gerontological counseling comes of age. Journal of Counseling and Development, 74(2), 143-149. The American Counseling Association. Reprinted with permission. No further reproduction authorized without written permission from the American Counseling Association:

http://www.counseling.org/

\section{Myers}

lion. Each of these projects addressed a different but related area, used the knowledge base developed in the preceding projects to educate project participants, and helped to raise the consciousness of counseling professionals of the need for services to the expanding older population. In addition, the cumulative effect of these national projects and the involvement of counselors and counselor educators nationwide led to a significant change in the organizational structure of ACA as reflected in a new division focused on adult development and aging.

\section{Aging Project 1 (1978-1979)}

ACA's first national project on aging was written in response to the 1972 ACA Senate resolution, as well as Salisbury's (1975) research and the identified lack of professional preparation opportunities in gerontological counseling. The basic argument presented to the AoA was that counselors were not being trained in this area because of lack of curricular resources to do so. Curriculum materials for preservice preparation of counselors were needed.

Counselors and counselor educators were identified and were brought together in four national workshops to review and evaluate a series of modules written by experts in aging and counseling, which were combined to form Counseling Older Persons: A Training Syllabus for Educators (Ganikos, 1979). Also produced was $A$ Handbook for Conducting Workshops on the Counseling Needs of Older Persons (Ganikos et al., 1979) and a slide tape presentation titled Hey, Don't Pass Me By! The syllabus and handbook were disseminated to all counselor education programs ( $N=$ approximately 475$)$ with a request that counselor educators develop coursework and use the syllabus as a textbook for gerontological counseling training.

\section{Aging Project 2 (1979-1981)}

It would be unrealistic to expect all counselor preparation programs to add new courses in gerontological issues. Even if all of them did so, the numbers of trained counselors could not be expected to be large enough to meet the mental health needs of the older population. ACA's second national project on aging approached these needs from the perspective of training paraprofessional and peer counselors to work with older persons. Such trained individuals could provide a minimal level of helping interventions, as well as referral for needed therapy before problems became severe (Waters, Reiter, White, \& Dates, 1979).

Three training manuals were produced in the second aging project, authored by both practitioners and researchers. The manuals were field tested in a series of five national workshops attended by counselors, counselor educators, and aging network personnel selected on the basis of identified expertise and interest in aging. When completed, the project materials were disseminated free of charge to all counselor preparation programs. The three Counseling Older Persons manuals were the following: Volume I: Guidelines for a Team Approach to Training (Myers, Finnerty-Fried, \& Graves, 1981), Volume II: Basic Helping Skills for Service Providers (Myers \& Ganikos, 1981), and Volume III: A Trainer's Manual for Basic Helping Skills (Myers, 1981). In addition, this project developed a national network of training programs using counselor educators, continuing education offices, and aging network staff to jointly plan and implement training programs for service providers to older persons.

\section{Aging Project 3 (1983-1984)}

In 1983, most counseling professionals working in the field had no specific training in gerontological counseling, because few counselor training programs provided courses in this area. This project attempted to increase the level of training and competence in gerontological issues among practitioners. Sixty counselors were selected from over 600 applicants (Phase I) to become gerontological counseling trainers (GCTs). The 60 GCTs were divided into four groups of 15 each and were provided with 2 days of intensive training in gerontological issues (Phase II). Each GCT then conducted at least two 1-day workshops in their local area for counseling practitioners (Phase III). By the time the project was completed, the GCTs had trained over 3,200 practicing professional counselors in basic aspects of aging and gerontological counseling, using curriculum materials developed in the first two national projects.

\section{Aging Project 4 (1988-1989)}

The fourth national project was based on the fact that persons live three fourths of their lives as adults and one third or more as older persons (over age 60). Thus, it is increasingly likely that all counselors, regardless of work setting, will encounter older persons and their families as clients. All counselors, therefore, should graduate and enter the profession with some basic knowledge of the needs of older persons and how to address those needs. By 1988, a fairly large volume of research was available concerning older persons. The challenge was to determine what information would be most relevant for all counselors, as opposed to those specializing in work with older people, and how best to integrate this information into existing counselor preparation curricula.

This project used the preparation standards of the Council for Accreditation of Counseling and Related Educational Programs (CACREP) as a basis for development of curricular units for training in gerontological issues. One unit on relevant gerontological issues was developed for infusion into each of the eight core curricular areas specified in the CACREP standards, including goals corresponding to the standards, a brief and extensive literature review and references, suggestions for audiovisual materials, classroom activities, and evaluation criteria. Guidelines for practica and internships as well as specialty training in gerontological counseling were included.

As part of this project, an extensive review of gerontological literature was conducted over a 1-year period. This literature is summarized in Infusing Gerontological Counseling Into Counselor Preparation: Curriculum Guide (Myers, 1989). A set of videotapes was developed to accompany the written Guide (Sweeney \& Myers, 1989, 1990). All of these materials were field tested in five regional workshops attended by a select group of practicing counselors, counselor educators, and aging network administrators and staff. At the conclusion of the project, the Guide was sent free of charge to all counselor preparation programs.

\section{Aging Project 5 (1989-1990)}

The fifth and last aging project focused on training outcomes as well as curricula. Using the materials developed in preceding projects, the project staff attempted to define competence in gerontological counseling. Two perspectives were addressed. First, what competencies relative to older persons could be expected of a counselor who graduated from any preparation program, assuming that gerontological issues had indeed been infused into the core curricula as defined by CACREP using the Guide developed in the fourth national aging project? Second, what competencies could be expected of a counselor who graduated with an intent to specialize in work with older people?

In developing a statement of gerontological competencies for counselors, a major challenge was to define what a counselor would 
Reprinted from Myers, J. E. (1995). From 'Forgotten and Ignored' to standards and certification:

Gerontological counseling comes of age. Journal of Counseling and Development, 74(2), 143-149. The American Counseling Association. Reprinted with permission. No further reproduction authorized without written permission from the American Counseling Association:

http://www.counseling.org/

Gerontological Counseling Comes of Age

be expected to know at the time they graduated with an entry-level degree, as opposed to what would be expected of an experienced practitioner. The competencies were developed through a series of five think-tank meetings attended by invited gerontological counselors, counselor educators, gerontologists, aging network personnel, and older persons.

To further disseminate the gerontological infusion model, a part of the fifth national project was the development of multiple-choice items, based on the generic competencies, which were submitted to the National Board for Certified Counselors (NBCC) for inclusion in the item pool for the National Counselor Examination. Items were also submitted for inclusion in the item pool for the National Certified Career Counselor examination. All of the items were field tested before submission to NBCC.

\section{Other Developments in ACA}

The five national projects described here were highly successful in stimulating interest in the counseling needs and concerns of older persons. ACA itself had supported a special committee on aging since the early 1970s. Over the years, the special committee identified as a major goal the development of interest groups on aging within each ACA division. Lack of support for standing committee status led to an alternative route to achieve association-wide support: the development of an organizational affiliate on adult development and aging. The ACA requirements for affiliates were that a minimum of 400 members be identified (and submit dues), 200 of which were new members to ACA. Within a year of its inception, the Association for Adult Development and Aging (AADA) gained more than 1,000 members, meeting the requirements for division status in 1986. The AADA now has more than 2,000 members and continues to grow.

Although many ACA divisions have maintained their interest groups on adult development and aging stimulated by the former national ACA committee, the AADA is the focal point within ACA for adult development and aging concerns. AADA formally endorsed the gerontological competencies, which have since served as the foundation for specialty preparation standards as well as specialty certification.

\section{SPECIALTY STANDARDS FOR GERONTOLOGICAL COUNSELING}

The AADA Committee on Standards used the competency statements, the Curriculum Guide, and available literature in gerontological counseling as the basis for developing a statement of professional preparation standards. This statement was submitted to the CACREP Board in 1990 and was revised for resubmission in 1991. After a review of the standards proposal by accredited training programs, CACREP voted in March of 1992 to approve the standards as a specialty emphasis within the existing community counseling standards. Counselor education training programs that are accredited in community counseling may elect to apply for the gerontological counseling specialty, if they meet the accreditation standards. At the time of this writing, several counselor education programs are known to be in the process of self-study to obtain recognition in this specialty, and one program has received recognition by CACREP in April 1995. The standards closely parallel the competency statements developed through the fifth ACA aging project. (A copy of the new standards is available from CACREP as part of the 1994 standards [Council for Accreditation of Counseling and Related Educational Programs, 1994].)

\section{NATIONAL CERTIFIED GERONTOLOGICAL COUNSELOR CREDENTIAL}

A final and significant part of ACA's fifth national aging project was the submission and presentation by project staff of a proposal to the NBCC to develop a specialty certification in gerontological counseling. Before voting in favor of the National Certified Gerontological Counselor (NCGC) proposal, the NBCC and the project staff conducted a survey of the (then) 1,700 members of AADA to determine need for and interest in a national specialty in gerontological counseling. The survey included five parts: (a) questions concerning intent to seek certification if available, (b) criteria the respondent thought should be required for individual certification (e.g., standards), (c) the respondent's training and experience in gerontological counseling, (d) demographic data, and (e) a self-assessment of competence for each of the minimum essential gerontological competencies.

Survey respondents $(N=346)$ expressed sufficient interest in a specialty certification to warrant the NBCC endorsing the proposal. Slightly over half of the 346 respondents $(n=177,51 \%)$ considered themselves to be qualified gerontological counseling practitioners, and more than half $(n=180,52 \%)$ indicated that they would seek a specialty certification in gerontological counseling if it were available. Only $10 \%(n=35)$ said they would not, whereas $38 \%(n=$ 132) were undecided.

Over half of the respondents $(n=201,58 \%)$ did not think a nationally certified counselor should be a requirement for the specialty certification, although this certainly is a requirement of the NBCC. Slightly fewer than half of the respondents $(n=166,48 \%)$ thought there should be an examination. Most of the respondents thought that appropriate training $(n=301,87 \%)$ and experience $(n$ $=242,70 \%)$ should be required. Only $53 \%(n=183)$ thought that appropriate supervision should be necessary. Letters of endorsement were considered most needed from supervisors $(n=156,45 \%)$ and least needed from employers $(n=59,17 \%)$. Audiotapes and videotapes were unpopular requirements, as evidenced by the fact that only $7 \%$ and $5 \%$ of respondents ( $n=24$ and $n=17$, respectively) chose these two items.

The NBCC voted to approve a national certification in gerontological counseling in January 1990. The NCGC credential is now awarded on the basis of a rigorous review of credentials and without a specialty examination. A major part of the application process is an assessment of competence by the applicant and his or her references based on the gerontological competency statements described in the next section. At the time of this writing, approximately 200 nationally certified counselors have received the NCGC credential, and NBCC is considering ways to recruit more persons to this specialty, or to alter the nature of the specialty to include mid-life as well as later life development (Elinor Waters, personal communication, July 11, 1994).

\section{GERONTOLOGICAL COMPETENCIES FOR COUNSELORS}

Gerontological Competencies for Counselors and Human Development Professionals (Myers \& Sweeney, 1990), the product of the fifth national ACA aging project, is a 38-page document that includes gerontological competencies in two areas: those for all counselors (generic), and those for counselors specializing (specialty) in work with older persons. The competencies, which were developed with broad input from counselors, gerontologists, practitioners, administrators, and researchers, are arranged according to each of the core 
Reprinted from Myers, J. E. (1995). From 'Forgotten and Ignored' to standards and certification:

Gerontological counseling comes of age. Journal of Counseling and Development, 74(2), 143-149. The American Counseling Association. Reprinted with permission. No further reproduction authorized without written permission from the American Counseling Association:

http://www.counseling.org/

Myers

curricular areas as well as identified areas of specialty preparation. They can be used by counselor educators in developing curricula and by practitioners to determine areas of competence for counseling with older persons.

To encourage dissemination and use of the competency statements by counselor educators ( 38 pages of competency statements is somewhat formidable), the project staff and participants developed a set of minimum essential gerontological competencies. Counselor educators developing gerontological curricula can use the full set of competencies or specific subsets as guidelines; however, it was anticipated that most educators would respond more favorably to a shorter and more easily assimilated document. Shown in Appendix A, the minimum essential statements constitute a "short form" of the gerontological counseling competency statements. Gerontological counselor specialists are expected to demonstrate both generic and specialty competencies, whereas counselors not electing to specialize in gerontological counseling would, ideally, demonstrate the minimum essential competencies for all counselors (generic). In reviewing these competencies, the reader should note that they are based on a model for infusion of concepts on aging into existing counselor preparation curricula as defined by CACREP.

Respondents to the NBCC survey mentioned earlier were asked to complete a self-assessment of their competence for each of the minimum essential gerontological competencies, using a 5-point Likert scale as follows: 1 = very competent, able to perform at a high level; 2 = competent, able to perform adequately; 3 = somewhat competent, more training required; $4=$ not competent, not able to perform at this time; and $5=$ not able to judge competence. The results of their self-assessments are shown in Table 1. In terms of generic competencies, the greatest level of competence was expressed for having positive, wellness-enhancing attitudes toward older persons $(M=1.2)$. This area also had the least variability of any of the competencies $(S D=0.56)$. The areas in which least competence was expressed were appraisal $(M=2.3)$, research $(M=2.3)$, and group procedures $(M=2.2)$. These also were the areas with the greatest amount of variability in responses $(S D s=0.96,0.94$, and 0.94 , respectively).

The greatest amount of competence in the specialty area was expressed for having positive, wellness-enhancing attitudes and a concern for empowerment over the life $\operatorname{span}(M=1.4)$. Again, there was little variability in the response to this item $(S D=0.72)$. The next highest ratings were given for competencies in the areas of human growth and development and the ability to function in multiple roles in working with older persons $(M=1.9)$. Variability in these two areas tended to be lower than in others $(S D=0.90$ and 0.91 , respectively). Areas in which the least amount of competence was expressed, and also which had the greatest variability in responses, were appraisal $(M=2.5, S D=1.00)$, research $(M=2.4, S D=$ $1.01)$, and group procedures $(M=2.4, S D=1.03)$.

The average amount of competence expressed for the generic competencies (the mean of the means given in Table 1) was 1.8, whereas the average for the specialty competencies was 2.1 . The average amount of variability in the two areas was 0.82 and 0.96 , respectively. In other words, respondents rated themselves as more competent according to the generic competencies than in regard to the specialty competencies, which would be expected as these represent a less intensive level of knowledge and skill. Most of the respondents considered themselves to be "somewhat competent" in each of the areas addressed but to need more training if they were to become "very competent" in each area. The low amount of variability in responses to the self-assessment may be indicative of the current state of knowledge of counselors nationwide.

\section{GERONTOLOGICAL COUNSELING: A LOOK TO THE FUTURE}

About one third of all counselor preparation programs now offer coursework to train counselors to work with older persons (Myers, 1989; Myers, Loesch, \& Sweeney, 1991). Many of these programs offer a specialization in this area as well. The numbers of student dissertations and theses and the numbers of articles in the professional literature related to older persons have increased dramatically in the last decade and may be expected to continue. With courses, standards, competencies, and a certification, it is clear that gerontological counseling is well established as a specialty within the counseling profession.

Nevertheless, it cannot be assumed that the gerontological counseling specialty will be self-perpetuating. If past history can be used to predict the future, strong leadership from the national level and

\section{TABLE 1}

\section{Self-Assessment of Competence in Gerontological Issues}

\begin{tabular}{lll}
\hline \hline Competency & $M$ & SD \\
\hline Generic competency & & \\
Wellness attitudes & 1.2 & 0.56 \\
Sensitivity to limitations & 1.5 & 0.77 \\
Helping relationships & 1.5 & 0.72 \\
Human development & 1.8 & 0.82 \\
Social and cultural foundations & 1.7 & 0.79 \\
Group procedures & 2.2 & 0.94 \\
Lifestyle and career & 1.9 & 0.88 \\
Appraisal & 2.3 & 0.96 \\
Research & 2.3 & 0.94 \\
Referral network, ethics & 2.0 & 0.91 \\
Specialty competencies & & \\
Empowerment & 1.4 & 0.72 \\
Human development & 1.9 & 0.90 \\
Social and cultural foundations & 2.1 & 0.94 \\
Multiple roles & 1.9 & 0.91 \\
Group procedures & 2.4 & 1.03 \\
Lifestyle and career & 2.1 & 1.00 \\
Appraisal & 2.5 & 1.00 \\
Research & 2.4 & 1.01 \\
Knowledge of needs & 1.9 & 0.89 \\
Interventions for physical and & 2.2 & 1.05 \\
mental impairment & & \\
Policy and legislation & 2.2 & 1.00 \\
Situational and developmental & 2.0 & 0.96 \\
interventions & & \\
Specialized therapies & 2.3 & 1.01 \\
Ethical issues & 2.0 & 0.97 \\
Consultation & 2.3 & 1.01 \\
Program development & 1.06 \\
\hline Not Scale ranges from & & \\
\hline
\end{tabular}

Note. Scale ranges from $1=$ very competent to $5=$ not able to judge competence. Refer to Appendix A for a complete listing of competencies. 
Reprinted from Myers, J. E. (1995). From 'Forgotten and Ignored' to standards and certification:

Gerontological counseling comes of age. Journal of Counseling and Development, 74(2), 143-149. The American Counseling Association. Reprinted with permission. No further reproduction authorized without written permission from the American Counseling Association:

http://www.counseling.org/

Gerontological Counseling Comes of Age

active advocacy at all levels will be required to maintain and enhance this specialty. National preparation standards are available, and specialty accreditation of training programs is possible. Counselor education programs need both encouragement and assistance in the specialty accreditation process, if the new accreditation is to receive support. National certification is available. Students and practitioners need to be encouraged to seek the NCGC credential. In addition, current and future NCGCs need to have access to training opportunities to maintain their certification. Because certification will require continuing education for maintenance of the NCGC credential, counselor educators need to be prepared to provide in-service education in gerontological counseling.

The results of the gerontological counseling certification survey, in combination with the history of ACA's aging projects, have implications for the future development of the specialty of gerontological counseling. After 15 years of curriculum development and training, the most obvious implication is the continued need for training to raise the level of competence of counselors in gerontological issues. Even those who consider themselves to be qualified gerontological counseling practitioners would like additional training to better serve their older clients. It also appears that advanced training is needed for those with some experience and competence in working with older people who want to develop higher levels of skill. With the gerontological counseling specialty in place, training must become a priority.

If the counseling profession is to prepare students in the gerontological counseling specialty and encourage practitioners to seek this additional specialty certification, the issue of jobs for trained gerontological counselors must also be addressed. Additional studies need to be conducted to determine available positions. ACA's advocacy efforts need to include attention to jobs in which mental health services for older persons are included and that currently are filled by social workers, psychologists, and other mental health care providers. The classifications for these positions need to be expanded to include counselors as possible employees. For example, legislation in most states mandates that social workers be hired in long-term care facilities. At present, no states require that counselors be hired in these settings. The Association for Gerontology in Higher Education is advocating with the Administration on Aging (AoA) and the federal congress to have all jobs funded through the AoA filled with persons with an associate, bachelor's, master's, or doctoral degree in gerontology. ACA also needs to work with the AoA, if counselors are to be included in AoA-funded positions.

The growth of interest in gerontological counseling, which has evolved over a relatively short time, is encouraging because ultimately it will benefit all of us as we grow older. The ultimate proof of interest and need lies not in the results of any one survey, the development of training standards, or the development of a specialty credential. Only time will reveal changes in the level of competence of counselors in gerontological issues and the quality of counseling services provided to, older persons. Outcome research, particularly studies that compare the effectiveness of trained gerontological practitioners with those without such training, is needed. A strong foundation for this specialty has been laid, but one cannot afford to sit back and assume it has enough momentum to carry forward on its own. As a profession, counselors continue to be challenged by the need to build a structure on that foundation with which we can live and grow comfortably. We must actively promote training, standards, certification, competence, and especially jobs for counselors if the mental health needs of older people are to be adequately met.
Finally, although the specialty is "in place," the need to train all counselors to respond to the mental health needs of older persons and their families remains a critical challenge. Indeed, if the infusion model discussed here and elsewhere were to be fully implemented in counselor training, perhaps the need for a gerontological counseling specialty would not be so great as it is now. Perhaps, as counselors continue to espouse a developmental perspective that views aging as a part of rather than apart from the life span, the need for a specialty will quietly disappear. Given a choice, I would argue for all counselors having some training to work with older people and their families, rather than just a few specializing in this area.

\section{REFERENCES}

American Association of Retired Persons. (1995). A profile of older Americans. Washington, DC: Author.

Blake, R., \& Kaplan, L. S. (1975). Counseling the elderly: An emerging area for counselor education and supervision. Counselor Education and Supervision, 15, 156-157.

Brammer, L. (1985). Counseling and quality of life for older adults: Beating the odds. Educational Perspectives, 23, 3-16.

Burns, B. J., \& Taube, C. A. (1990). Mental health services in general medical care and in nursing homes. In B. S. Fogel, A. Furino, \& G. Gottlieb (Eds.), Protecting minds at risk (pp. 321-330). Washington, DC: American Psychiatric Association.

Burnside, I. (1984). Working with the elderly: Group processes and techniques. Monterey, CA: Wadsworth.

Cohen, G. (1977). Mental health services and the elderly: Needs and options. In S. Steury \& M. L. Black (Eds.), Readings in psychotherapy with older people (pp. 68-72). Rockville, MD: National Institute of Mental Health.

Council for Accreditation of Counseling and Related Educational Programs. (1994). CACREP accreditation standards and procedures manual. Alexandria, VA: Author.

Flemming, A. S., Rickards, L. D., Santos, J. F., \& West, P. R. (1986). Report of a survey of community mental health centers (Vol. I). Washington, DC: White House Conference on Aging.

Ganikos, M. L. (1979). Counseling the aged: A training syllabus for educators. Alexandria, VA: American Association for Counseling and Development.

Ganikos, M. L., \& Grady, K. A., Olson, J. B., Blake, R., Fitzgerald, P., \& Lawrence, P. C. (1979). A handbook for conducting workshops on the counseling needs of older persons. Alexandria, VA: American Association for Counseling and Development.

Herr, J. J., \& Weakland, J. H. (1979). Counseling elders and their families. New York: Springer.

Howard-Jasper, J. (1981). APGA's involvement in aging. In J. E. Myers, P. Finnerty-Fried, \& C. Graves (Eds.), Counseling older persons: Vol. I. Guidelines for a team approach to training (pp. 187-192) . Alexandria, VA: American Counseling Association.

Knight, B. G. (1989). Outreach with the elderly: Community education, assessment, and therapy. New York: New York University Press.

Kunkel, M. A., \& Williams, C. (1991). Age and expectations about counseling: Two methodological perspectives. Journal of Counseling and Development, 70, 314-320.

Myers, J. E. (1981). Counseling older persons: Vol. III. A trainer's manual for basic helping skills. Alexandria, VA: American Association for Counseling and Development.

Myers, J. E. (1989). Infusing gerontological counseling into counselor preparation: Curriculum guide. Alexandria, VA: American Association for Counseling and Development.

Myers, J. E., \& Blake, R. (1986). Professional preparation of gerontological counselors: Issues and guidelines. Counselor Education and Supervision, 26, 137-145.

Myers, J. E., Finnerty-Fried, P. F., \& Graves, C. (1981). Counseling older persons: Vol. I. Guidelines for a team approach to training. Alexandria, VA: American Association for Counseling and Development. 
Reprinted from Myers, J. E. (1995). From 'Forgotten and Ignored' to standards and certification:

Gerontological counseling comes of age. Journal of Counseling and Development, 74(2), 143-149. The American Counseling Association. Reprinted with permission. No further reproduction authorized without written permission from the American Counseling Association:

http://www.counseling.org/

Myers

Myers, J. E., \& Ganikos, M. L. (1981). Counseling older persons: Vol. II. Basic helping skills for senvice providers. Alexandria, VA: American Association for Counseling and Development.

Myers, J. E., Loesch, T. J., \& Sweeney, T. J. (1991). Trends in gerontological counselor preparation. Counselor Education and Supervision, 30, 194-204.

Myers, J. E., \& Sweeney, T. J. (1990). Gerontological competencies for counselors and human development professionals. Alexandria, VA: American Association for Counseling and Development.

Palmo, A. J., Weikel, W. J., \& Brooks D. K. (Eds.). (1995). Foundations of mental health counseling (2nd ed.). St. Louis, MO: Charles C Thomas.

Piggrem, G. W., \& Schmidt, L. (1982). Counseling the elderly. Counseling and Human Development, 14, 1-12.

Poggi, R. G., \& Berland, D. I. (1985). The therapists' reactions to the elderly. The Gerontologist, 25, 508-513.

Salisbury, H. (1975). Counseling the elderly: A neglected area in counselor education and supervision. Counselor Education and Supervision 14, 237-238.

Special Committee on Aging, U.S. Senate. (1983). Developments in aging, 1983. Washington, DC: U.S. Government Printing Office.

Sweeney, T. J., \& Myers, J. E. (1989). Infusing gerontological counseling into counselor preparation: Video resources (Parts 1-4). Alexandria, VA: American Association for Counseling and Development.

Sweeney, T. J., \& Myers, J. E. (1990). Infusing gerontological counseling into counselor preparation: Video resources (Parts 5-7). Athens, OH: New Hope Enterprises.

Thompson, L. (1987). Comparative effectiveness of psychotherapy for depressed elders. Joumal of Consulting and Clinical Psychology, 55, 385-390.

Waters, E. (1984). Building on what you know: Individual and group counseling for older people. The Counseling Psychologist, 12, 52-64.

Waters, E., Reiter, S., White, B., \& Dates, B. (1979). The role of the paraprofessional peer counselor in working with older people. In M. L. Ganikos (Ed.), Counseling the aged: A training syllabus for educators (pp. 227-264). Alexandria, VA: America Counseling Association.

\section{APPENDIX A}

\section{GERONTOLOGICAL COMPETENCIES FOR COUNSELORS}

\section{A. Minimum Essential Gerontological Competencies for All Counselors (Generic)}

1. Exhibits positive, wellness-enhancing attitudes toward older persons, including respect for the intellectual, emotional, social, vocational, physical, and spiritual needs of older individuals and the older population as a whole.

2. Exhibits sensitivity to sensory and physical limitations of older persons through appropriate environmental modifications to facilitate helping relationships.

3. Demonstrates knowledge of the unique considerations in establishing and maintaining helping relationships with older persons.

4. Demonstrates knowledge of human development for older persons, including major psychological theories of aging, physiological aspects of "normal" aging, and dysfunctional behaviors of older persons.

5. Demonstrates knowledge of social and cultural foundations for older persons, including common positive and negative societal attitudes, major causes of stress, needs of family caregivers, and the implications of major demographic characteristics of the older population (e.g., numbers of women, widows, increasing numbers of older minorities).

6. Demonstrates knowledge of special considerations and techniques for group work with older persons.

7. Demonstrates knowledge of lifestyle and career development concerns of older persons, including the effects of age-related phys- ical, psychological, and social changes on vocational development, factors affecting the retirement transition, and alternative careers and lifestyles for later life.

8. Demonstrates knowledge of the unique aspects of appraisal with older persons, including psychological, social, and physical factors that may affect assessment, and ethical implications of using assessment techniques.

9. Demonstrates knowledge of sources of literature reporting research about older persons and ethical issues in research with older participants.

10. Demonstrates knowledge of formal and informal referral networks for helping older persons and ethical behavior in working with other professionals to assist older persons.

\section{B. Minimum Essential Competencies for Gerontological Coun- seling Specialists (Specialty)}

1. Demonstrates and actively advocates for positive, respectful, wellness-enhancing attitudes toward older persons and a concern for empowerment of persons throughout the life span.

2. Demonstrates skill in applying extensive knowledge of human development for older persons, including major theories of aging, the relationship between physical and mental health and aging, the difference between normal and pathological aging processes, genderrelated developmental differences, and coping skills for life transitions and loss.

3. Demonstrates skill in applying extensive knowledge of social and cultural foundations for older persons, including characteristics and needs of older minority subgroups, factors affecting substance and medication misuse and abuse, recognition and treatment of elder abuse, and knowledge of social service programs.

4. Demonstrates the ability to function in the multiple roles required to facilitate helping relationships with older persons (e.g., advocate, family consultant) and to mobilize available resources for functioning effectively in each role.

5. Demonstrates skill in recruiting, selecting, planning, and implementing groups with older persons.

6. Demonstrates skill in applying extensive knowledge of career and lifestyle options for older persons, age-related assets and barriers to effective choices, and resources for maximizing exploration of career and lifestyle options.

7. Demonstrates skill in appraisal of older persons, including identifying characteristics of suitable appraisal instruments and techniques and in using assessment results in developing treatment plans.

8. Demonstrates skill in applying extensive knowledge of current research related to older persons and the implications of research findings for helping relationships.

9. Demonstrates skill in applying extensive knowledge of the intellectual, physical, social, emotional, vocational, and spiritual needs of older persons and strategies for helping to meet those needs.

10. Demonstrates skill in applying appropriate intervention techniques, in collaboration with medical and other care providers, for physical and mental impairments common to older persons, such as acute, chronic, and terminal illness, depression, suicide, and organic brain syndromes.

11. Demonstrates extensive knowledge of the formal and informal aging networks, public policy, and legislation affecting older persons, and knowledge of a continuum of care that will allow older persons to maintain their highest level of independence.

12. Demonstrates skill in applying appropriate intervention techniques for situational and developmental crises commonly experi- 
Reprinted from Myers, J. E. (1995). From 'Forgotten and Ignored' to standards and certification:

Gerontological counseling comes of age. Journal of Counseling and Development, 74(2), 143-149. The American Counseling Association. Reprinted with permission. No further reproduction authorized without written permission from the American Counseling Association: http://www.counseling.org/

Gerontological Counseling Comes of Age

enced by older persons, such as bereavement, isolation, divorce, relocation, sexual concerns, illness, transportation, crime, abuse, and relationships with adult children and caregivers.

13. Demonstrates skill in the use of a wide variety of specialized therapies to assist older persons in coping with both developmental and nonnormative issues, such as creative arts therapies, pet therapy, peer counseling, and family counseling.

14. Demonstrates skill in applying extensive knowledge of ethical issues in counseling older persons, their families, and care providers.

15. Demonstrates the ability to act as a consultant to individuals and organizations on issues related to older persons and their families.
16. Demonstrates skill in program development for the older population, including needs assessment, program planning, implementation, and evaluation.

Jane E. Myers is a professor in the Department of Counseling and Educational Development at the University of North Carolina at Greensboro. (Note: This article was accepted for publication by Charles Claiborn in 1991. The author chose to delay publication in consideration of the contents of this special issue of JCD on counseling specialties.) Correspondence reganding this article should be sent to Jane E. Myers, University of North Carolina, Department of Counseling and Educational Development, 1000 Spring Garden, Greensboro, NC 27412. 
Reprinted from Myers, J. E. (1995). From 'Forgotten and Ignored' to standards and certification:

Gerontological counseling comes of age. Journal of Counseling and Development, 74(2), 143-149. The American Counseling Association. Reprinted with permission. No further reproduction authorized without written permission from the American Counseling Association: http://www.counseling.org/

Copyright of Journal of Counseling \& Development is the property of American Counseling Association and its content may not be copied or emailed to multiple sites or posted to a listserv without the copyright holder's express written permission. However, users may print, download, or email articles for individual use. 